\title{
As influências (psico)pedagógicas belgas em Faria de Vasconcelos e a repercussão na educação das crianças 'anormais' (escolares)
}

\author{
(The influence of Belgian (psycho)pedagogy on António de Sena \\ Faria de Vasconcelos and on the education of 'abnormal' children)
}

\author{
Ernesto CANDEIAS MARTÍNS \\ Escola Sup. De Educaçâo, Castelo Branco
}

\begin{abstract}
RESUMO: Faria de Vasconcelos (1880-1939) foi um escolanovista com grande projeção na ciência pedagógica da época, ao estudar os problemas escolares dos anormais pedagógicos e deficientes. Dedicou parte da sua obra e ações sobre essa temática, refletindo e criando instituições para colmatar e resolver muitos desses problemas dos 'anormais escolares' e jovens na escolha da sua profissão, propondo métodos apropriados de intervenção, escolas especiais e especialização dos professores. A argumentação assenta numa metodologia hermenêutica de análise às publicações daquele pedagogista e outras fontes da época norteando-nos pelos seguintes objetivos: compreender a perspetiva de Vasconcelos sobre a educação/ensino dos anormais escolares; analisar as ideias e ações deste pedagogo na pedagogia contemporânea e/ou da pedologia e enquadradas no Movimento da Escola Nova; aprofundar o seu papel no Instituto de Reeducação Mental Pedagógica (1929-32) dedicado a realizar exames e intervenções às crianças 'anormais' e outras ações paralelas. 0 período histórico de abordagem, percorre os inícios do séc. XX, coincidente com a permanência de Vasconcelos na Bélgica (1904-14) e, posteriormente a sua ação em Portugal (1925-32) dedicada às crianças 'anormais pedagógicos'. A pedagogia especial sobre 'anormais' teve uma difusão de ideias psicopedagógicas, psiquiátricas e psicotécnica impregnando o pensamento e intervenções de Vasconcelos na sua obra.
\end{abstract}

PALAVRAS-CHAVE: Faria de Vasconcelos; Pedologia; ensino dos anormais; anormais pedagógicos; Instituto Reeducação Mental e Pedagógica.

ABSTRACT: António de Sena Faria de Vasconcelos (1880-1939) was a Portuguese educator, a follower of the progressive New School movement, and a prominent figure in the field of pedagogical science of the time. Part of his work was devoted to studying and solving the educational problems of pedagogically 'abnormal' and disabled children and young people through the development of special schools, specialised teachers and specially adapted teaching methods. This article is based on a hermeneutic analysis of Faria de Vasconcelos's publications and other sources from the time. The aims of the study are: to understand Vasconcelos's approach to the education of 'abnormal' children; to analyse his ideas and 
actions in the context of the New School Movement and their influence on contemporary pedagogy and paedology; and to examine his role in the Institute of Mental and Pedagogical Reeducation (1929-32) for the study and treatment of 'abnormal' children. The analysis covers the first four decades of the twentieth century, from Vasconcelos's time in Belgium (1904-14) to his creation of the Institute of Occupational Guidance in Lisbon in 1925 and continued work on behalf of pedagogically 'abnormal' children. The special pedagogy of 'abnormal' children was found in psycho-pedagogy, psychiatry and psychotechnical theory, and had a profound influence on Vasconcelos's work and ideas.

KEYWORDS: Faria de Vasconcelos; paedology; education of 'abnormal' children; pedagogical abnormality; Institute of Mental and Pedagogical Reeducation.

\section{Introdução}

António Faria de Vasconcelos (1880-1939) foi o pedagogista português, ligado ao Movimento da Escola Nova, mais conhecido no estrangeiro, com um itinerário educacional de vida académica em vários países no âmbito da Pedagogia e Psicologia, um interventor social e cívico em revistas e sociedades de estudos, com uma imensa produção científica e ações (psico) pedagógicas realizadas dentro e fora do seu país, que the mereceram análises histórico-educativas ou pedagógicas em vários aspetos, ${ }^{1}$ por exemplo: 0 homem no contexto da sociedade; as questões sociais da educação e as ideias pedagógicas inovadoras da Escola Nova (métodos e estratégias de ensino); o surgimento da pedologia e a forma como a criança deve ser educada cientificamente; a pedagogia dos 'anormais escolares' com reflexões e aplicação de metodologias de diagnóstico nas escolas, nas tutorias de Infância e nas instituições de reeducação; 0 papel do médico e professor na escola (higienismo escolar e social); a colaboração 'família-escola; a formação de educadores e professores no desenvolvimento de competências e no conhecimento das caraterísticas dos seus alunos antes de ensiná-los; a pedotecnia (orientação escolar e profissional) e/ou psicotecnia para os jovens no mercado de trabalho (qualificar a profissão); os aspetos psicológicos relacionadas com a escolha de profissão e aprendizagem escolar, de tal modo que foi considerado por Hélio Carpintero, ${ }^{2}$ um dos maiores psicólogos portugueses; a reforma dos sistemas educativos (na Bolívia e mentor da Proposta de Reforma do Sistema Educativo Português de João Camoesas, em 1923); etc.

Vasconcelos viveu num período sociohistórico que produziu uma mudança de paradigma pedagógico, orientada para o estudo cientifico da criança e na análise aos perío-

\footnotetext{
${ }^{1}$ Ernesto Candeias Martins (coord.), António Faria de Vasconcelos nos meandros do Movimento da Escola Nova: Pioneiro da Educação do Futuro (Castelo Branco: Edição Câmara Municipal Castelo Branco Nárzea Rainha Imp., 2019); Ernesto Candeias Martins, " 0 ideário científico-pedagógico do escolanovista Faria de Vasconcelos (1880-1939) em prol duma escola nova, inovadora e atual”, EccoS Revista Científica (Uninove-SP-Brasil), $n^{\circ} 48$, jan./mar. (2019): 363-383; Jaime Lopes Dias, "ltinerário biobibliográfico de Faria de Vasconcelos", Estudos de Castelo Branco -Revista de H. ${ }^{a}$ e Cultura -Monográfico, $\mathrm{n}^{0} 30$ (1-7) (1969): 83-109; M. Gabriel Moreno Bulas Cruz, "António Sena Faria de Vasconcelos (1880-1939: um português no movimento da Escola Nova". Educação em Revista, 2 (1), (2001): 139-148.

${ }^{2}$ Helio Carpintero, Historia de la Psicología en España (Madrid: Pirámide, 2004).
} 
dos de infância e adolescência feita por um caleidoscópio de áreas científicas (medicina, psiquiatria, biologia, psicologia, fisiologia, sociologia e práticas pedagógicas), que impregnaram os discursos sociopedagógicos, o experimentalismo e a pedagogia científica sobre a criança na época. Estes contributos permitiram aos educadores e/ou professores intervir educacionalmente para melhorar as capacidades intelectuais, sociais, estéticas e profissionais das crianças (incluindo as 'anormais escolares e patológicas').

Nesta frágua de ideias do início do século passado divulga-se com insistência os termos de 'educação nova', 'escola nova', 'pedagogia científica e experimental', entre outros, numa rutura com os princípios, a organização escolar, os conteúdos curriculares e as finalidades da escola e dos sistemas educativos, oriundos do séc. XVIII. De facto, 0 movimento das 'Escolas Novas' reagiu contra a escola tradicional acompanhando 0 progresso da sociedade industrial, com a intenção de formar pessoas e profissionais capazes, independentemente das suas caraterísticas individuais. ${ }^{3}$ Ora esta amálgama de conhecimentos científico-(psico) pedagógicos não foram alheios a Vasconcelos, os quais começaram a germinar-se no seu pensamento durante a permanência na Bélgica (1902-14) e Suíça (1915).

Todo este cenário científico-pedagógico europeu provocou modificações políticas, propostas educativas, iniciativas inovadoras expressas por associações/movimentos (professores, pedagogos, intelectuais ou cientistas da educação/social), experiências em escolas, etc. que transformaram 0 ambiente educativo e formativo no conhecimento efetivo da criança e do aluno. Vasconcelos na primeira década do século XX vem ocasionalmente a Portugal para participar em congressos pedagógicos (março/1909 pela Liga Nacional de Instrução), ${ }^{4}$ dar lições de pedologia e pedagogia experimental na Sociedade de Geografia de Lisboa, ${ }^{5}$ ou realizar estudos de educação sobre crianças 'anormais' (1908).

Neste texto abordaremos um dos temas preferidos de Faria de Vasconcelos: a pedagogia dos 'anormais escolares', desde o estudo científico e diferenciação na educação/ ensino escolar relativamente aos normais. Este interesse pelos problemas (escolares) dos anormais, provém da sua estadia na Bélgica e retomado no seu regresso a Portugal,

\footnotetext{
${ }^{3}$ Ressaltamos desses postulados da pedagogia contemporânea, com um carácter de unidade essencial na multiplicidade de doutrinas e teorias, na intenção de reconciliar essas diferencias doutrinais, incluindo a tendência de renovação do naturalismo pedagógico, da pedagogia da ação, pedagogia individual, ativa, social, cultural e filosófica e das tendências psicológicas e experimentalismo. Vid. Ernesto Candeias Martins, "0 movimento da escola nova e as tendências educativas geradas ao longo do séc. XX numa encruzilhada de teorias e práticas" In: A Educação Comparada para além dos números. Contextos locais, Realidades nacionais e Processos transnacionais, editado por Carla Galego, Ma Manuel Calvet Ricardo \& António Teodoro (Lisboa: Edições Universitárias Lusófonas/ULH, 2019), 110-121.

${ }^{4}$ Vid. António Faria de Vasconcelos, "These -Anormais", In: $2^{\circ}$ Congresso Pedagógico de Instrução Primária e Popular. Liga Nacional de Instrução (Lisboa: Imprensa Nacional, 1909), 347-354; Macedo de Oliveira, "2. Congresso Pedagógico de Instrução Primária -Liga Nacional de Instrução Primária", Occidente -Revista Illustrada de Portugal e do Estrangeiro, n. ${ }^{\circ} 1092$ (30/abril) (1909), com acesso ao link http://hemerotecadigital. cm-lisboa.pt/OBRAS/0cidente/0cidente.htm

${ }^{5}$ António Faria de Vasconcelos, Lições de Pedologia e Pedagogia Experimental (Lisboa: Antiga Casa Bertrand, 1909).
} 
na década de 20, ao criar o Instituto de Orientação Profissional (IOP), em 1925, e 0 Instituto de Reeducação Mental e Pedagógico (IRMP), em 1929, fazendo-0 aprofundar, experimentar e refletir aspetos de pedologia, pedotecnia, psicometria e psicologia (infantil), que se vivia nos inícios do séc. XX. Através de uma metodologia hermenêutica (analítica) interpretaremos esta temática em Vasconcelos, servindo-nos da sua obra compilada por J. Ferreira Marques e de publicações avulsas, ${ }^{6}$ assim como outras fontes e estudos psicopedagógicos da época, considerados por nós essenciais ao enquadramento histórico-educativo, nos princípios do séc. XX, de modo a podermos abordar 0 ambiente universitário belga, a experiência da escola de Biérges, as figuras de Decroly, Lemoor, A. Binet, Claparède, a ação no IOP e o ensaio pedagógico no IRMP, etc. Em súmula, toda a parte documental utilizada permitiu-nos analisar, direta ou indiretamente, elementos relevantes de informação, contextualização e reflexão sobre a pedologia e pedagogia dos anormais escolares.

Norteamo-nos pelos seguintes objetivos: compreender a perspetiva de Faria de Vasconcelos sobre a educação/ensino dos anormais escolares (conceptualização), na época; analisar as ideias e ações de Vasconcelos e respetivos contributos à pedagogia contemporânea e pedagogia dos 'anormais'; interpretar a vertente da pedologia em Faria de Vasconcelos, enquadrada no Movimento da Escola Nova (experiência na Escola de Biérges); aprofundar as ações psicopedagógicas de Vasconcelos no IRMP (1929-1932) em relação à educação dos 'anormais'. 0 período histórico de abordagem percorre os inícios do séc. XX com a chegada de Vasconcelos à Bélgica até à sua ida para a Suíça (1914 até 1915) e, posteriormente, a sua ação em Portugal (1925-32), no IRMP, onde fazia rastreio às crianças ditas 'anormais pedagógicos', em simultâneo com as funções no IOP.

0 ensino dos anormais escolares devia ser, segundo Vasconcelos, uma preocupação do Estado, pois havia muitas crianças afastadas do ensino regular devido às suas limitações na aprendizagem, às taras de degenerescência, que eram produzidas pelo ambiente envolvente e pela hereditariedade e, ainda a deficiências (sensitivas, mentais, psicológicas) que manifestavam. Havia, pois a necessidade de uma pedagogia especial que resolvesse os problemas escolares e introduzisse métodos psicopedagógicos e de

\footnotetext{
${ }^{6}$ Joaquim Ferreira Marques, Faria de Vasconcelos - Obras Completas, Vol. I (1900-1909) (Lisboa: FCG, 1986); Ibid. Faria de Vasconcelos - Obras Completas, Vol. II (1915-1920) (Lisboa: FCG, 2000); Joaquim Ferreira Marques, Faria de Vasconcelos - Obras Completas, Vol. III (1921-1925) (Lisboa: FCG, 2006); Joaquim Ferreira Marques, Faria de Vasconcelos - Obras Completas, Vol. IV (1925-1933) (Lisboa: FCG, 2009); Joaquim Ferreira Marques, Faria de Vasconcelos - Obras Completas, Vol. V (1933-1935) (Lisboa: FCG, 2010a); Joaquim Ferreira Marques, Faria de Vasconcelos - Obras Completas, Vol. VI (1936-1939) (Lisboa: FCG, 2010b); Cfr. António Faria de Vasconcelos, Une école nouvelle en Belgique (Paris/Neuchâtel: Delachaux \& Niestlé, 1915); António Faria de Vasconcelos, Uma Escola Nova na Bélgica, traduzida por Carlos Meireles-Coelho, Ana Cotovio e Lúcia Ferreira (Aveiro: UA Editora, Univ. de Aveiro, 2015); António Faria de Vasconcelos, Monographie de L'Institut de Reeducaction Mentale et Pedagogique (Lisboa: Imprensa Lucas \& Ca, 1931); António Faria de Vasconcelos, Lições de Pedologia e Pedagogia Experimental; António Faria de Vasconcelos «Anormais»", In: $2^{\circ}$ Congresso Pedagógico de Instrução Primária e Popular. Liga Nacional de Instrução; Manuela Alves, "Compilação de Obras do Prof. Faria de Vasconcelos", Estudos de Castelo Branco - Revista de História e Cultura, n ${ }^{\circ} 30$ (1-7) (1969): 112-119; etc.
} 
diagnóstico (testagem, exames) que permitisse classificar esses anormais (educáveis), que determinasse 0 tipo de instituição de ensino onde podiam ingressar, a organização escolar e apoios. Ora esta temática da anormalidade pedagógica dos alunos vai preencher manuais de pedagogia para uso na formação dos professores, com definições dessas crianças que não podiam aprender como as crianças da sua idade (as ditas normais). Ou seja, para essas crianças 'anormais' (fisiológicos, mentais, psíquicos, sensitivos) exigia-se 0 apoio simultâneo de médicos e professores, com classes especiais de aperfeiçoamento (atrasados mentais) e/ou em institutos especializados.

\section{Faria de Vasconcelos e 0 influxo das ideias (psico)pedagógicas belgas (1902-14)}

Faria de Vasconcelos parte em 1902 para a Bélgica, após a conclusão do seu curso de direito em Coimbra matriculando-se na Universidade Nova de Bruxelas (Faculdade Ciências Sociais) como cientista social preocupado pelas questões do homem e da educação, com a intenção de aprofundar saberes em pedologia, pedagogia experimental, pedotecnia e/ou orientação profissional e pedagogia especial. Em 1903 publica a obra La Psychologie des Foules Infantiles, ${ }^{7}$ referente ao trabalho final do curso, onde defende a reorganização de escolas no sistema educativo, de modo a controlar a emergência de comportamentos antissociais, a indisciplina e a criminalidade infantojuvenil na época. Frequenta e conclui $01 .^{\circ}$ Doutorado Ciências Sociais naquela universidade com a tese Esquisse d'une théorie de la sensibilité sociale, em 1904, ${ }^{8}$ tendo sido premiado com 'Louvor e distinção' e, por isso, convidado a ser professor no Instituto de Altos Estudos, entre 1904-14 na disciplina 'Psicologia e Pedagogia' e admitido como membro da Comissão Executiva da Sociedade Belga de Pedotecnia. Simultaneamente experimenta os ideais do movimento da escola nova em Biérges-les-Wavre (1912-14), que foi cotada com 28,5 pontos dos 30 estabelecidos pela Oficina Internacional das Escolas Novas, ficando à frente de outras escolas novas conceituadas. ${ }^{9}$

Ao eclodir a invasão alemã da I Guerra Mundial exilia-se na Suíça recebendo apoio de A. Ferrière, E. Claparède e Bovêt no Instituto J.J. Rousseau (curso de Ciências da Educação) onde lecionou pedagogia e, paralelamente abre uma escola na casa de Ferrière, em Vaud, para rapazes e raparigas. Neste meandro de influxos de ideias, de experimentações, de debates e reflexões científicas sobre a criança e as suas anormalidades, que afloravam na Bélgica (e Europa), Faria de Vasconcelos irá estabelecer os pontos essenciais da evolução da ciência da educação e da pedologia, no seio da educação nova, nos princípios do séc. XX. ${ }^{10}$

\footnotetext{
${ }^{7}$ Joaquim Ferreira Marques, Faria de Vasconcelos - Obras Completas, Vol. I (1900-1909), 95-110.

${ }^{8}$ Ibidem, 111-186.

${ }^{9}$ A publicação de António Faria de Vasconcelos, Une école nouvelle en Belgique (Paris/Neuchâtel: Delachaux \& Niestlé, 1915), foi traduzida a várias línguas, com Prefácio de Adolphe Ferrière, que considera Vasconcelos "ce pionnier de l'éducation de l'avenir" (p. 10). Em 2015 houve tradução portuguesa: António Faria de Vasconcelos, Uma Escola Nova na Bélgica (Prefácio de Adolphe Férrière, Pósfácio e Notas de Carlos Meireles Coelho), tradução do francês por Carlos Meireles-Coelho, Ana Cotovio e Lúcia Ferreira (Aveiro: UA Editora -UAveiro - FCT, 2015).

${ }^{10}$ António Faria de Vasconcelos, Lições de Pedologia e Pedagogia Experimental, 25.
} 
Para o efeito interessa-nos destacar os conhecimentos científico-pedagógicos, as experiências psicopedagógicas, 0 contacto com figuras universitárias, culturais ou intelectuais no ambiente belga - vertente da psicologia e psiquiatria infantil, ${ }^{11} \mathrm{e}$ que, de uma forma direta ou indireta, influenciaram o pensamento de Faria de Vasconcelos, em especial, sobre a educação dos 'anormais escolares'.

\section{Ambiente universitário difusor de ideias e enfoques educativos}

Bélgica era um pais, que desde a unificação em 1830 (Norte flamengo e língua próxima ao holandês; Sul francófono e língua próxima à alemã), apresentava diferentes grupos sociais e uma pluralidade cultural, linguística, religiosa e económica, ${ }^{12}$ sendo uma nação de encontros e eventos ( $1^{\circ}$ Congresso de Paidologia em Bruxelas -1911); de associações (Sociedade Belga de Paidotécnia -1906, Sociedade Belga de Pedotecnia -1909), de cursos e seminários atrativos para universitários e bolseiros estrangeiros; de difusão de ideias novas (paidologia, psicologia infantil, de testes de aptidões, inteligência e habilidades) e experiências científicas (escolas e laboratórios); Bélgica era capital internacional da proteção da infância e patronato, na transformação das prisões e instituições penitenciárias em escolas de beneficência e educação para crianças/jovens desvalidas e infratoras (reformas desde 1840 a 1914 por Édouard Ducpétiaux e Jules LeJeune). Ou seja, um espaço e ambiente propício para debates entre tendências de livre pensamento, de trocas de saberes que circulavam em países europeus e na América. Tratava-se dum país com várias visões científicas, ideológicas e religiosas, em que a nova ciência positiva, onde se incluíam a psicologia e a sociologia — com um enfoque materialista do homem e fundadas em ideias da fisiologia e biologia (teoria evolucionista de Darwin e positivismo de Spencer) - , permitia novas reflexões. Havia nesta amálgama de ideias duas razões de visão do mundo e do homem: a científica com preponderância do positivismo e evolucionismo; e a religiosa mais conservadora.

0 progresso exigia estudos científicos sobre a educação/formação e 0 Movimento das Escolas Novas, produzindo referentes para: 0 âmbito tecnológico e transformação industrial com novas exigências de ensino-aprendizagem; o sentimento democrático e de formação dos cidadãos (educação cívica); a expansão da pedagogia científica, preocupada pelas diferenças individuais e pelas crianças anormais (escolares e deficientes); as novas metodologias alternativas de ensino; a investigação na infância e adolescência; 0 avanço da psicologia e biologia; melhorar a sociedade e mudar as condições socioeconómicas da população (extensão da educação/sistema escolar); etc.

Ora as experiências de escolas novas faziam aprofundar esse estudo científico sobre a 'infância-educação' e dos anormais. Neste ambiente científico surgem figuras pioneiras na paidologia-pedologia, como 0. Decroly, J. loteyko (1866-1928), A. G. Christiaens

\footnotetext{
11 Vid. Marc N. Richelle et al., "Psychology in Belgiun", Annual Review of Psychology, 43 (1992): 505-529; Joaquim Ferreira Marques, "Perspectivas internacionales en la historia de la psicología en Portugal", Revista de Psicología General y Aplicada (Madrid), 53 (4), (2000): 599-606.

12 Vid. José Ramón Larraz, La evolución económica de Bélgica (Madrid: Ed. Blass, 1946).
} 
(responsável da Office Intercommunal pour l'Orientation Professionelle e diretor do Instituto de Orientação profissional de Bruxelas), ${ }^{13}$ Van Biervlier, G. Rouma (responsável pela reforma liberal na Bolívia), ${ }^{14}$ Sluys, Schuyten, J. Demoor, A. Ley, G. Vermeylen, ${ }^{15}$ etc., assim como, o aparecimento de várias revistas (Revue Pedotechnie, em 1913). Todos os conhecimentos eram abordados nos círculos académicos, em debates públicos e em instituições de formação de professores, o que fez surgir várias Escolas Normais (Bruxelas e na província de Charleroi e Mons), ofertas de cursos e seminários de paidologia e sobre problemas escolares (lecionados por loteyko), para além de vária publicações, de teor didático e socioeducativo.

No início do séc. XX a Bélgica possuía três afamadas universidades:

- Universidade de Lovaina (origem no séc. XV) com a destacável figura do Cardeal Mercier (1851-1926) e dos seus discípulos (os espanhóis J. Zaragüeta e Pe. Marcelino Arnaiz), para além de outros professores que abordavam temas de filosofia, educação e a dialética cultural e religiosa da época, tendo criado o Laboratório de Psicologia Experimental que era frequentado por alunos de todo mundo.

- Universidade Livre de Bruxelas francófona e cosmopolita (criada em 1834 por Pierre-Théodore Verhaegen com o lema "Scientia vincere tenebras"), que estava assente nos valores de liberdade de pensar, em discursos sobre materialismo, positivismo e humanismo, destacando-se a difusão de ideias sobre psicologia, feita pelo seu reitor Guillaume Tiberghein (1819-1901), krausista liberal e progressista, influenciado pelas ideias de Spencer, mas enfrentado com os católicos, para além do psiquiatra G. Vermeylen e médico Jules Bordet. Esta universidade, com 0 seu Instituto de Sociologia fundado em 1902, apresentava um enfoque interdisciplinar, incluindo ao nível da investigação. Muitos professores estavam ligados ao movimento maçónico. Decroly deu alguns cursos nesta universidade.

- Universidade Nova de Bruxelas (1894-1919), onde estudou e foi professor Faria de Vasconcelos. Era cosmopolita assente no distintivo do símbolo da árvore (saberes ministrados), destacando-se o reitor Guillaume De Greef e outros professores de renome, alguns deles sociólogos, médicos, pedagogos e políticos liberais (Paul Janson, E. Picard, Elie Lambette, Paul A. Solier, Eurico Ferri, É. Vandervelde, Louis de Brouckere, etc.), dedicados à investigação.

Em 1919 as Universidades Livre e a Nova fundiram-se constituindo a Universidade de Bruxelas. Havia ainda outras universidades, como as de Gante e Liége onde J. Del Boeuf (1831-1896) divulgava a psicofísica, a psicologia científica de Fechner, Helmholtz,

\footnotetext{
${ }^{13}$ António Faria de Vasconcelos, "Princípios fundamentais do método de A. G. Christiaens". Boletim do Instituto de Orientação Profissional, $n^{0}$ 26, junho (1938): 3-7.

${ }^{14}$ Ernesto Candeias Martins, "G. Rouma e Faria de Vasconcelos nas Missões Belgas (1909 a 1920): Dos ideais da Escola Nova à Reforma Educativa liberal boliviana", En: Influencias Belgas en la Educación Española e Iberoamericana, coordenado por José M${ }^{a}$ Hernández Díaz (Salamanca: Ediciones Universidad de Salamanca, 2019), 385-396.

${ }^{15}$ Vid. Guillaume Vermeylen, Lois débiles mentales (Madrid : Hernaudo Ed., 1926).
} 
W. Wundt e o positivismo. Bélgica tinha também universidades populares como a de Marcinelle (1904) organizada por um grupo de trabalhadores que abordavam a instrução e educação do povo, em complemento do ensino oficial, com cursos, conferências e diversas atividades comunitárias. Esta funcionalidade das universidades populares foi tida em conta por Vasconcelos aquando da sua docência na Universidade Popular de Lisboa (1921).

As ideias novas do movimento educacional impregnavam os estudos educativos no meio universitário, e também as propostas de reforma educativa, como a de 1914, impulsada por Leon De Paeuw (Inspetor Geral de educação primária) e materializada em 1918, em debates política educativa e publicações, como as do educador flamengo Edward Peeters sobre educação especial (mutilados guerra). A globalização da educação escolar belga fez aprofundar a natureza científica da criança, a periodização do seu desenvolvimento natural (etapas da infância, puberdade, adolescência, juventude) materializada em observações, medições e quantificações em várias áreas científicas. 0s dados experimentais, provenientes de estudos com 'anormais' em instituições educativas, originaram 0 uso do conceito de 'normalidade escolar' (e social), o qual se impôs como norma para o desenvolvimento humano nas etapas da infância-juventude. No ano de 1897 criou-se em Bruxelas uma escola de ensino especial para crianças anormais pedagógicas e para outras categorias, com 0 fim de proteger a infância em perigo. Passou-se, assim para uma legitimação conceptual na distinção e separação entre 'anormais' e normais ao nível escolar e social

Convém indicar que as ideias à volta da pedagogia moderna, no ambiente intelectual belga, como noutros lugares de Europa, fizeram surgir a aplicação de testes nas escolas (Binet e Simon) e a distinção de anormais de hospício e escolares, ${ }^{16}$ uma nova organização científica do trabalho, novos discursos de legitimidade social para organização pedagógica, o poder social dos médicos no âmbito educativo, cultural e na militância cívico-política, a definição de políticas e anovadas intervenções (higienismo), e também investigações em psiquiatria infantil. Faria de Vasconcelos não foi alheio a todo este emaranhado de ideias pedagógicas, filosóficas, sociológicas e psicológicas, especialmente da educação nova e das experiências pedagógicas nas escolas de países europeus. ${ }^{17}$

\section{A viragem na pedagogia: da pedologia à pedagogia especial sobre 'anormais'}

A Europa assistiu no início do séc. XX ao fulgor das ideias de Lombroso, relativas à correlação entre instinto de criminalidade e genética, aos estudos de Ribot relacionadas com a herança no comportamento humano, ao surgimento das primeiras seções infantis nos asilos (psiquiatria), aos tribunais para crianças ('kinderkoer'-1854) administrados pelos Irmãos da Caridade, á distinção entre anormalidades psíquicas e atrasados (idio-

\footnotetext{
${ }^{16}$ Vid. Alfred Binet et Thomas Simon, Les enfants anormaux. Guide pour l'admission des enfants dans les classes de perfectionnement (Toulouse: Privat, 1905).

${ }^{17}$ Nathalie Duval, "L'Éducation nouvelle dans les sociétés européennes à la fin du XIXe siècle", Revue Histoire, Économie \& Société (SEDES), année 21 (1) (2002): 71-86.
} 
tas), a clínicas psiquiátricas com critérios de avaliação à inteligência e às conceções pedagógicas do Movimento de Escolas Novas acreditando no benefício dessa educação inovadora. Esta viragem preocupou vários quadrantes políticos, científicos, religiosos, jurídicos, médicos e pedagogos, na base da defesa social sobre a criança e conceção infância/juventude, originando diversas reformas belgas: trabalho infantil (1899); escolas de caridade (1891) e beneficência e educação em vez de prisões; asilos para crianças atrasadas (Bruxelas em 1897, Antuérpia em 1898); criação de tribunais para menores (1912) e legislação de proteção; declarou a escolaridade obrigatória (1914); desenvolveu-se a psiquiatria (exames, testes, técnicas) orientada para a infância; etc.

Nesta panóplia de tendências de pensamento educativo destacam-se epistemologicamente: 0 eixo sociológico comum à vertente determinista biológica e a relativista cultural; e 0 eixo psicológico, com a psicologia racional e experimental. Estas tendências combinavam-se dentro das ciências da educação, diferindo de país para país, ${ }^{18} \mathrm{com}$ as suas metodologias (lições das coisas, centros de interesses, pedologia experimental, método de projetos) provenientes dos saberes experimentais. Por sua parte, Claparède na sua obra Psychologie de l'enfant et pédagogie expérimentale (1905) atribuiu as bases científicas dessa nova educação aos seus estudos de psicologia da infância e às ideias sobre educação funcional. Igualmente Adolphe Ferrière (fundador do Bureau International des Écoles Nouvelle, Genève-1899) empenha-se na divulgação dos princípios das escolas novas, sintetizando no plano internacional distintas correntes pedagógicas preocupadas com a criança/infância, para além de, Roger Cousinet de dar uma atenção especial ao âmbito social da educação escolar.

Todas estas ideias e muitas outras de teor filosófico, psiquiátrico, psicológico e sociológico estavam na mente de estudiosos, em especial a dedicação aos anormais. A paidologia e/ou de pedologia, como ciência nova, segundo Vasconcelos, ${ }^{19}$ intentava abranger os problemas referentes à natureza física e psíquica da criança, cuja solução se encontrava no âmbito da experimentação, na educação natural e lógica da criança. Assim, este pedagogista define a pedologia como "[...] fisiologia experimental da criança, cujo corpo e espírito procura conhecer, tudo em vista a determinação não só das leis do seu desenvolvimento físico e mental", próprias de todas as crianças, mas apenas "[...] diferenças, variedades e tipos individuais", ${ }^{20}$ ou seja, um conjunto de problemas respeitantes ao seu crescimento (mental) às variedades individuais e daí 0 estudo científico sobre a criança. ${ }^{21}$

Deste modo, a pedagogia (especial) sobre as crianças anormais surge no meio belga, apesar da conceção de educabilidade do tipo de infância ter começado em França com Itard (idiotas eram educáveis com o método fisiológico de treino), seguido de Esquirol as suas propostas para a educação dos jovens idiotas e atrasados, e de Séguin, impulsor

\footnotetext{
${ }^{18}$ Bernard Charlot, Les sciences de l'éducation. Un enjeu, un défi (Paris: ESF, 1995), 38.

${ }^{19}$ Joaquim Ferreira Marques, Faria de Vasconcelos - Obras Completas, Vol. I (1900-1909),198 e 199.

${ }^{20}$ Ibidem, 205.

${ }^{21}$ Ibidem,189 e 191.
} 
duma escola especial privada em 1843 e de várias publicações, onde demonstra a necessidade médico-pedagógica e a criação de escolas especiais. A responsabilidade era médica e pedagógica o que implicava a inclusão dessas crianças (regime de alienados) com as respetivas consequências jurídico-sociais. Pretendia-se isolar esses 'anormais' para evitar os impactos negativos à ordem social.

Vejamos como, entre muitas figuras de pedagogistas belgas com as suas ações e publicações no campo da pedologia, psicometria e pedotecnia e da educação dos anormais na escola, há alguns que marcaram pela sua projeção científico-pedagógica, 0 pensamento de Faria de Vasconcelos.

(A)- A figura de Ovide Decroly. Este pedagogo belga considerou a biologia como 0 modelo gerador de todas as aproximações científicas, já que a evolução filogenética se manifestava na criança, em especial as que viviam no campo, pois livremente expressavam os seus interesses e podiam brincar e jogar. Apostava na mudança da escola, pois ela não cumpria os seus propósitos nem respeitava a originalidade da criança. Ela devia responder às condições biológicas do aluno (necessidades e interesses) e 0 ensino devia estar organizado com métodos ativos em função do seu desenvolvimento, o qual está em constante evolução físico e mental e adaptação ao meio social onde vive. Ao criar a Sociedade Belga de Pedotecnia (1905) investiga as aplicações práticas da pedologia, clarifica a ação dos educadores, destaca a importância da vigilância médico-sanitária às crianças (anormais), a prevenção de doenças, a despistagem das crianças irregulares escolares, ${ }^{22}$ e a adequação da organização escolar às possibilidades físicas e mentais dos alunos. Todas estas ideias baseiam-se no princípio da globalização, dos centros de interesse, da associação de ideias e metodologia de ensino (leitura), incluindo a educação dos anormais. Para Decroly, tal como para Faria de Vasconcelos, dever-se-ia institucionalizar o tratamento dessas crianças 'anormais' ou irregulares, na base médico-pedagógica, proporcionando-Ihes um regime mental e corporal individualizado, apoiado no conhecimento constante do seu estado psicológico e fisiológico.

Decroly aposta por uma estruturação escolar natural, reprodutora da estratificação social, com um sistema escolar e tutelar amplo, onde a disciplina, o programa e o regime se adequassem às crianças anormais, distinguindo nelas as educáveis (escolares) e ineducáveis (asilos, hospícios, hospitais). 0 caráter seletivo dos mecanismos sociais estava na origem das diferentes capacidades das crianças, considerando que não se entendia 0 valor educativo da integração e comunicação entre alunos de distintas capacidades. ${ }^{23}$ 0 seu contacto com alunos 'irregulares', na base dum enfoque multidisciplinar (pedagógico e médico, com prevalência da psicologia), confirmava-lhe o insucesso dos procedimentos e métodos tradicionais e, por isso, propôs um ensino-aprendizagem apoiado

\footnotetext{
22 Ovide Decroly, Estudios pedagógicos y psicológicos sobre el niño anormal (Madrid: CEPE, 1993): 24-25. Vid. Joaquim Ferreira Gomes "A école de L'ermitage de Ovide Decroly". Revista Portuguesa de Pedagogia. Ano III, $\mathrm{n}^{\circ}$ 1 (1962): 139-144 (Coimbra: Faculdade de Letras - IEPP, 1962)

${ }^{23}$ Ovide Decroly, El niño anormal (Madrid: Beltrán, 1934): 29-35.
} 
na experiência pessoal e na descoberta e, para tal estabeleceu bases fundamentais de adaptação:

a) à pedagogia genética (observação);

b) à psicologia da criança (reações e esquema de análise dos fatores biológicos, fisiológicos, afetivos, intelectuais e secundários) para adotar individualmente os procedimentos didáticos; um modelo de aprendizagem da linguagem (leitura e escrita);

c) à medição da inteligência (escala métrica de inteligência - provas);

d) à função da globalização (perceção sincrética e gestáltica);

e) aos novos conhecimentos de psicologia, psicometria, da ciência da educação no rendimento escolar;

f) e a renovação dos espaços e da organização na escola, para além de definir as crianças irregulares e profilaxia de tratamento. ${ }^{24}$

0 pedagogo belga lutou contra as classificações existentes, por serem insuficientes, intentando uma certa uniformidade ao agrupar anormais por causa intrínseca e anormais por causa extrínseca (caracteres fisiológicos e biológicos) e com subgrupos. ${ }^{25} \mathrm{~A}$ sua classificação de anormais incluía aqueles: por defeito ou lesão (aleijados, atrofiados); por defeito sensorial (cegos, surdos-mudos); por defeito mental (idiotas, imbecis); por defeitos afetivos (loucos morais); por defeito do sistema nervoso (epiléticos); e por deformação proveniente do meio envolvente. De entre todas estas variações, Decroly dedicou-se muito às anormalidades mentais, afetivas e do sistema nervoso, delineando estratégicas para a escolarização dessas crianças, separando entre as que iam para um hospital e as que tinham educação física e moral, não admitindo a junção delas.

Faria de Vasconcelos, ${ }^{26}$ considerava que "já se compreende que, diferindo às crianças umas das outras, se devem antes subordinar os métodos de ensino às necessidades individuais da criança, tendo em atenção as particularidades fisiológicas e psicológicas de cada uma". Essa captação de indícios cabia ao professor de forma holística antes de utilizar os métodos de ensino e os conteúdos curriculares, mas essa competência deveria ser adquirida na sua formação inicial. Contudo, aquele pedagogo ressaltava em Decroly o papel das aulas especiais, sendo inseparáveis a educação geral e a especial, mas propugnava em todo caso uma pedagogia diferenciada. ${ }^{27}$ Igualmente Decroly e de Boulanger, ${ }^{28}$ constitui uma referência fundamental para 0 sistema judicial de proteção

\footnotetext{
${ }^{24}$ Ibid., Estudios pedagógicos y psicológicos sobre el niño anormal, 80-101 (quadro).

${ }^{25}$ Joaquim Augusto Ferreira da Fonseca, Estudos Médico-Sociais sobre a Proteção a menores anormais $e$ delinquentes (Lisboa: Tip. do Reformatório Central de Lisboa, 1930): 21-25

${ }^{26}$ Joaquim Ferreira Marques, Faria de Vasconcelos - Obras Completas, Vol. I (1900-1909), 192

${ }^{27}$ Ovide Decroly, Problemas de psicología y pedagogía (Madrid: Beltrán, 1929): 23-35.

${ }^{28}$ Estes pedagogos criaram em 1913 a Clínica de Observação de Mole, em 1914, a Clínica Médico-Pedagógica de Brabante.
} 
de menores na Bélgica, nomeadamente na definição dos processos de observação, diagnóstico e metodologia médico-pedagógica. ${ }^{29}$

(B)-Foram igualmente muito influentes as figuras de Jean Demoor e de Auguste Ley. 0 primeiro foi um médico/pedagogo da Escola de Anormais de Bruxelas, colaborador de Decroly, e os seus estudos coincidiram com os de Binet, tendo publicado um manual de abordagem às crianças em idade escolar. ${ }^{30} \mathrm{~A}$ sua classificação prática de anormais atrasados pedagógicos (insuficiência mental, vagabundagem ou falta apoio escolar) e de atrasados médicos (causas mórbidas e alterações, cretinos, incapazes de vontade e atenção, sem responsabilidade e atividade psíquica limitada) requeria um diagnóstico e uma intervenção psicopedagógica e médica/psiquiátrica. No caso dos atrasados pedagógicos alegava que uma má influencia do meio, a falta de educação e certas doenças infantis causavam inclinações e hábitos nas crianças, que as tornava incapazes e lentas na aprendizagem, causando um transtorno para as normais. Só uma intervenção individualizada, sem recurso a castigos sistemáticos e um bom ambiente e alimentação reeducaria os atrasados pedagógicos. Por outro lado, Auguste Ley foi médico e professor na Universidade Livre e trabalhou com Demoor em escolas com crianças atrasadas, tendo refletido sobre o papel da psiquiatria (infantil) e do Estado nas crianças anormais, especialmente as atrasadas (agrupadas entre as que nasciam assim e as que nasciam em função do meio) e as alienadas.

Os estudos destes médicos belgas incidiram sobre crianças idiotas (profundas, mais leves), merecedoras de institucionalização. Ambos consideravam que essas crianças não eram incuráveis e intratáveis sendo a favor da profilaxia social, da criação de instituições (observar e praticar a psiquiatria), de infraestruturas especializadas, material didático novo, formação profissional e especialização aos professores em escolas especiais, etc. Assim, as atividades da psiquiatria proliferaram na Bélgica, com muitas figuras celebres (Guilhaume Vermeylen, Fernand D'Hollander, Marcel Alexander, Alfred Dupureux em Ghent, Louis e Paul Vervaeck), ${ }^{31}$ desde a fundação da Sociedade para Proteção de Crianças Anormais, através de discursos e de eventos, com criação de instituições especializadas, surgimento do movimento de higiene mental (1914) e a formação de inspetores e profissionais habilitados com conhecimentos médico-psiquiátricos.

(C)- Medard Schuyten e o seu influxo em Vasconcelos. Este psicólogo realizou estudos paidológicos e de aplicação de métodos pedagógicos para conhecer os problemas da criança. Propôs em Amberes, o serviço de 'paidologia' (laboratório em 1899), anexo às escolas municipais e fundou uma Sociedade de Paidologia com respetivo boletim difusor (1912) e, ainda várias publicações onde incidia sobre o objetivo de precisão e rigor do

\footnotetext{
${ }^{29}$ Vid. Albano Ramalho, Impressões sobre as Escolas de França e Bélgica (Porto: Casa Editora de A. Figueirinhas, 1909).

${ }^{30}$ Vid. Jean Demoor, As crianças anormais e o seu tratamento educativo em casa e na escola (Lisboa: C \& Editora, 1922); Les bases scientifiques de l'éducation (Bruxelles: Imp Université Libre, 1900).

${ }^{31}$ Benoîte Majerus \& Veerle Massin, "Des psychiatres et des enfants : une histoire belge autour du congrès de 1937", Revue d'Histoire d'Enfant 'Irrégulier', nº 18 (2016): 149-166.
} 


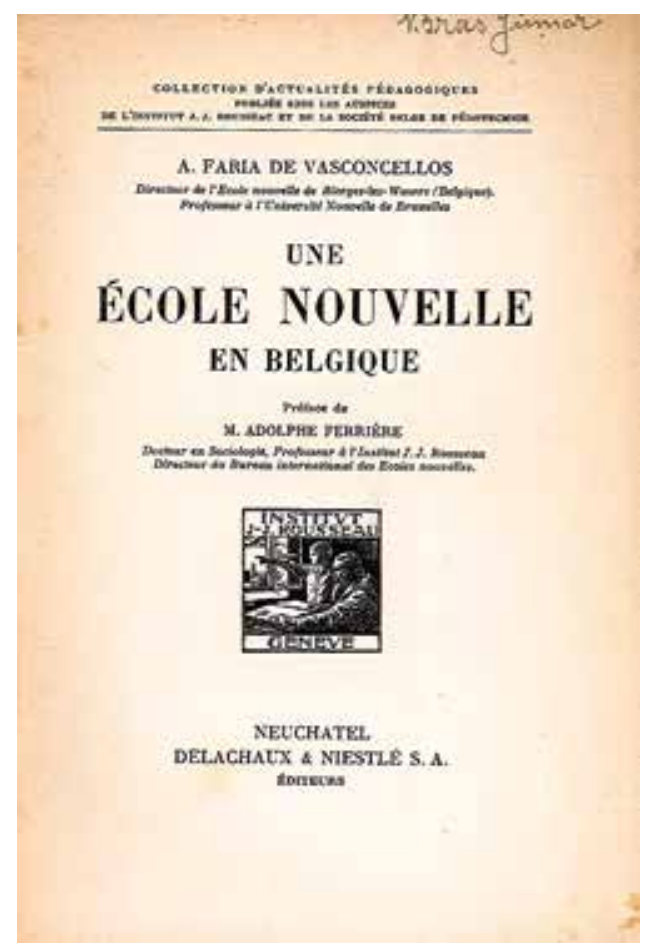

Faria experimentou os ideais do movimento da escola nova em Biérges-les-Wavre (1912-14), que foi cotada com 28,5 pontos dos 30 estabelecidos pela Oficina Internacional das Escolas Novas.

método experimental, com uso a estatísticas (observação e experimento), orientando a pedagogia científica à investigação no âmbito escolar e, por isso, defendia uma pedagogia renovada na base de investigação à educação/ensino escolar (influxo higienista) e à didática. Este amigo de Vasconcelos, influenciado pelo positivismo e psicologia, considerava a pedagogia experimental na dicotomia de ciência pedagógica dos fins e a ciência pedagógica dos meios empíricos em contexto escolar (medida e medição de testes de Binet \& Simon, Claparède, Decroly).

A abordagem à anormalidade da infância exigia vários estudos, ${ }^{32}$ provenientes: do movimento paidológico e/ou pedológico internacional, que não conseguia consolidar a pedologia como ciência da criança e daí a proliferação de publicações; dos pedagogos que pretendiam soluções aos problemas escolares (classificar os alunos para analisar as suas necessidades) e a generalização educativa (políticas educativas e de orientação escolar e profissional); dos investigadores no estudo científico da criança, que impregna-

${ }^{32}$ Vid. Monique Vial, Les enfants anormaux à l'école : aux origines de l'éducation spécialisée, 1882-1909(Paris: Colin, 1990). 
vam a pedagogia de ideias provenientes da psicologia, da medicina, da psiquiatria e da sociologia; e por parte dos agentes sociais preocupados na proteção e reformas sociais sobre a infância abandonada, indisciplinada e delinquente. De facto, a anormalidade devia ser analisada na vertente física (fisiológica, anatomia patológica), psíquica (sinais, exploração psiquiátrica) e pedagógica (problemas de atraso e de aprendizagem). Proliferou-se, assim, no meio belga vários estudos científicos, congressos, criação de aulas/ classes ou instituições, etc. Muitos médicos pedagogistas e/ou psiquiatras pretenderam abordar as diferenças entre 'anormal-normal', a partir de testes aplicados nas escolas (Binet-Simon), com implementação de métodos para a segregação desses coletivos, servindo de base aos reformadores sociais no delineamento de políticas sociais e medidas integradas. Ora essas práticas realizadas, fundamentadas conceptualmente fez que muitas crianças (débeis ou anormais) fossem suscetíveis de reeducação/correção, inaugurando-se no âmbito da psicologia e/ou pedologia (corretiva, curativa) a ideia de corrigir 'taras', prescindindo dos discursos de eugenesia, biotipologia e determinismo para a consideração de educáveis. Deste modo, as experiências psicopedagógicas demonstraram a aplicação aos anormais os meios de educação e metodologias dos ditos normais.

\section{Experiência prática de uma 'Escola Nova' em Biérges por Faria de Vasconcelos}

Faria de Vasconcelos aprofundou na prática as ideias de educação nova ao realizar a experiência da Escola Nova em Biérges-les-Wavre (1912-14), ${ }^{33}$ com localização rural e espaços para aprendizagem e atividades, seguindo muitos aspetos de escola ao ar livre na época. ${ }^{34} \mathrm{~A}$ escola, rodeada por um parque natural e ambiente montanhoso, compunha-se de dois edifícios para aulas, um deles destinado a oficinas (serralharia, carpintaria, modelagem, cartonagem, desenho, encadernação) e laboratórios (física, química) dando aos alunos uma vida social com alegria e entusiasmo, onde a cultura física e intelectual, educação moral e artística mereciam uma especial atenção formativa. Em termos avaliativos havia um Comité de Patronage, composto por ilustres figuras, ${ }^{35}$ que acompanhavam a experiência pedagógica, a qual foi visitada por vários pedagogistas

\footnotetext{
${ }^{33}$ Esta escola começou com 9 alunos no $1 .^{\circ}$ ano em 1912, no 2. ${ }^{\circ}$ ano em 1913 tinha 25 alunos e, por fim no $3 .^{\circ}$ ano, em 1914, havia 35 alunos para uma capacidade de 60 vagas. Elaborou uma brochura 'LÉcole Nouvelle à la Campagne' para os pais explicando-Ihes os objetivos da escola inserida no movimento das Escolas Novas e de ser a primeira na Bélgica.

${ }^{34}$ No âmbito da História da Educação a expansão das escolas ao ar livre, inspiradas em instituições existentes no séc. XIX e inícios do XX sugerimos consultar: Vid. Marc Nicolas Gilbert et al., "A escola ao ar livre. Uma experiência pedagógica e arquitetónica na Europa do século XX”, História da Educação, 105 (2005): 101-106; Anabela Amaral, "Aprender a palavra ao ar livre. Estratégia de modernidade sanitária em Portugal no início do séc. XX”. História. Revista da FLUP(UPorto), IV série, vol. 6 (2016): 41-55.

${ }^{35}$ Destacavam-se neste Comité: 0 responsável da direção, embaixador brasileiro na Bélgica Oliveira Lima; Alves da Veiga (embaixador de Portugal na Bélgica); Gabriel Compayré (téorico da pedagogia, reitor Academia de Lyon, inspetor-geral da Instrução pública e professor - Escola Normal de Fontenay-aux-Roses/Saint Cloud); Adolphe Ferrière; Ovide Decroly; Guillaume De Greef (reitor/professor da Univ. Nova de Bruxelas); T. Jonckheere (professor na Facudade de F. ${ }^{\mathrm{a}}$ e Letras da Univ. Nova de Bruxellas e diretor da Escola Normal); Maurice Maeterlinck (Prémio Nobel da Literatura-1911); V. Devogel (diretor das Escolas de Saint-Gilles - Bruxelas); N. Smelten (diretora de escola e secretária-geral da Liga de Ensino e da Sociedade Belga de Pedotecnia); Paul Sollier (psiquiatra neurologista e professor na Universidade Nova de Bruxelas); Medard Carolus Schuyten
} 
(entre eles Álvaro de Lemos, em setembro de 1913). Vasconcelos partia do princípio de que a educação dos sentimentos sociais só é possível pela prática duma vida social bem compreendida e, por isso, cultiva-se os sentimentos de responsabilidade e poder de iniciativa em liberdade, confiança em si mesmo, independência, coragem, vontade, tenacidade e entusiasmo pelo trabalho, criando assim na criança uma verdadeira individualidade e uma grande sociabilidade.

Em Biérges exercia-se: a vida familiar em larga escala (self-government), ${ }^{36}$ onde professores-alunos viviam juntos e partilhando refeições e atividades; a vertente artística conjugava-se com o ensino e prática livre da pintura, desenho, música e visitas exteriores a exposições e museus, passeios e recreios; e a atividade na lavoura onde se aprendia a vida económica e pequenas questões judiciais. Tudo concorria para uma educação estética e racional dos jovens.

Com a fundação da Liga Internacional Pró-Educação Nova, em 1921, que teve grande impacto em Portugal, estabeleceu-se, em definitivo, uma conceção moderna da pedagogia que, apesar de imperfeitamente realizada e, simultaneamente criticada, dominará 0 universo educacional ao longo do séc. $X X^{37}$. Todo o cenário da nova educação remete-nos, de forma implícita ou explícita, para a matriz das ideias da pedagogia contemporânea, impregnada pelo espírito científico, que para Vasconcelos tinha o contributo de várias ciências "[...] cujas aquisições e métodos Ihe servem para melhor estudar, compreender, interpretar os factos e os problemas pedagógicos. Por outro lado, trata os factos, problemas e processos pedagógicos com um critério próprio, como factos naturais e positivos". ${ }^{38}$

Essas áreas científicas irão constituir, as ciências da educação, com contributos importantes para 0 estudo científico da criança, ${ }^{39}$ já que a "[... ] ciência educativa consiste na educação pedagógica das famílias", na formação de professores e, principalmente a impregnação das ideias científicas de pedologia, psicologia e pedotecnia no conhecimento do "[...] corpo da criança (estatura, peso, etc.) normal ou anormal, a sua evolução, os órgãos dos sentidos, o seu espírito, as qualidades e defeitos físicos, intelectuais e morais, tendo em vista a determinação das leis do seu desenvolvimento físico e mental". ${ }^{40}$ Esses princípios da Escola Nova chegam a Portugal, consolidando uma matriz científica no

(pedólogo e diretor/professor do Dept ${ }^{0}$ Pedologia de Antuérpia na Univ. Nova de Bruxelas entre 1899-1923); A Nyns (inspetor escolar em Bruxelas); Émile Ad. Gustave Verhaeren (Univ. Católica de Lovaina) e J. Holsworth.

${ }^{36}$ Carlota Boto, "Faria de Vasconcelos e a Escola Nova em Portugal: do self-government à educação científica", Revista Brasileira de História da Educação, 19 (2019): 1-16.

${ }^{37}$ Joaquim Ferreira Marques, Faria de Vasconcelos - Obras Completas, Vol. I (1900-1909), 224; Álvaro Viana Lemos, Princípios basilares da Liga Internacional de Educação Nova e seus fins (Coimbra: Tip. Reis Gomes, 1929).

${ }^{38}$ António Faria de Vasconcelos, "As características de educação contemporânea”, Seara Nova (Lisboa), 15/ outubro (1921): 17

${ }^{39}$ Joaquim Ferreira Marques, Faria de Vasconcelos - Obras Completas, Vol. I (1900-1909),194-195.

40 Ibidem, 198. 
estudo da criança e dos seus processos educativos, atraindo intelectuais que dão consistência a esse pensamento pedagógico, ${ }^{41}$ e realização de experiências em escolas. ${ }^{42}$

\section{A pedagogia de ensino dos 'anormais' em Faria de Vasconcelos}

No princípio do séc. XX a anormalidade e a criança anormal não tinha definições unívocas, já que a atenção que se dava era as situações escolares e as crianças com problemas pedagógicos. Essa problemática de anormalidades circunscrevia-se: à conceção da criança e do seu estudo científico (pedologia, paidologia); e à capacidade da criança, que integrava a instrução pública na época, para ser educada ou não, o que dependia da sua tipologia. Os médicos e os psicopedagogos diagnosticavam essas anormalidades escolares recorrendo a testes (A. Binet \& T. Simon). ${ }^{43}$

De facto, 0 advento da pedagogia baseada em fundamentos científicos, tal como era delineada em vários países como a Bélgica e Suíça, foi um terreno fértil para a psicologia, a psiquiatria ou para a vertente médico-pedagógica no tratamento dos atrasados mentais ou anormais patológicos, que a escola excluía, apesar dos esforços educativos. Surge, assim 0 interesse subsidiário das ciências médico-pedagógicas, psicológicas e sociais para com essas problemáticas dos anormais que motivou estudos e reflexões dos pedagogos, psicólogos, médicos e sociólogos (relações jurídico-sociais com delinquentes, abandonados, indisciplinados). Conceptualmente não havia unanimidade nos termos utilizados por psicólogos e psiquiatras, pois havia diferentes critérios e/ou classificações, com um leque de divisões e subdivisões (educáveis e ineducáveis, difíceis e incertos, idiotas, imbecis, débeis de inteligência, de carácter, etc.), dentro do estado anormal da criança. Daí ter haver um certo entrosamento entre os discursos científico-pedagógicos com os discursos médicos, políticos e jurídicos.

Efetivamente, a pedagogia dos 'anormais' era um termo usado em comparação com a educação das crianças ditas normais escolares, na possibilidade de serem educáveis esses alunos com anomalias (sensitivas, mentais, antissociais). Ou seja, aquela pedagogia abordava as limitações das capacidades dos alunos que condicionavam o seu percurso escolar ou procurava melhorar de forma correlativa a sua educação, relacionando-se com a possibilidade ou não de educação, em comparação com os alunos ditos normais. 0 reconhecimento da anormalidade facilitava 0 trabalho do professor na determinação pedagógica de como intervir com 0 aluno normal, possibilitando-Ihe a construção de uma

\footnotetext{
${ }^{41}$ Mencionamos: Adelaide Cabete, Adolfo Coelho, Adolfo, Lima, Afonso Duarte, Agostinho de Campos, Alberto Pimentel Filho, Alfredo Bensaúde, Alves dos Santos, Álvaro Viana de Lemos, António Sérgio, Aurélio da Costa Ferreira, Aurélio Quintanilha, Costa Sacadura, Emílio Costa, Fernando Payart Ferreira, João de Barros, Marques Leitão, Pedro José da Cunha, Tomás da Fonseca, etc. Vid. Manuel Henrique Figueira, Um roteiro da Educação Nova em Portugal (Lisboa: Livros Horizonte, 2004).

${ }^{42}$ A Escola Oficina $n^{0} 1$ (Lisboa), Escola Prática Comercial de Oliveirinha, Escola Comercial Raúl Dória (Porto), a Casa Pia de Lisboa, o Colégio Militar, o Instituto de Odivelas e Instituto de Pupilos do Exército em Lisboa, Escola Normal Primária de Benfica (Lisboa), Colégio-Liceu Figueirense (Figueira da Foz), Colégio Moderno (Coimbra), Instituto Moderno (Porto), Ginásio Madeira no Funchal, Escola Agrícola de Coimbra.

${ }^{43}$ Alfred Binet \& Thomas Simon, Les enfants anormaux: guide pour l'admission des enfants anormaux dans les classes de perfectionnement, 34-47.
} 

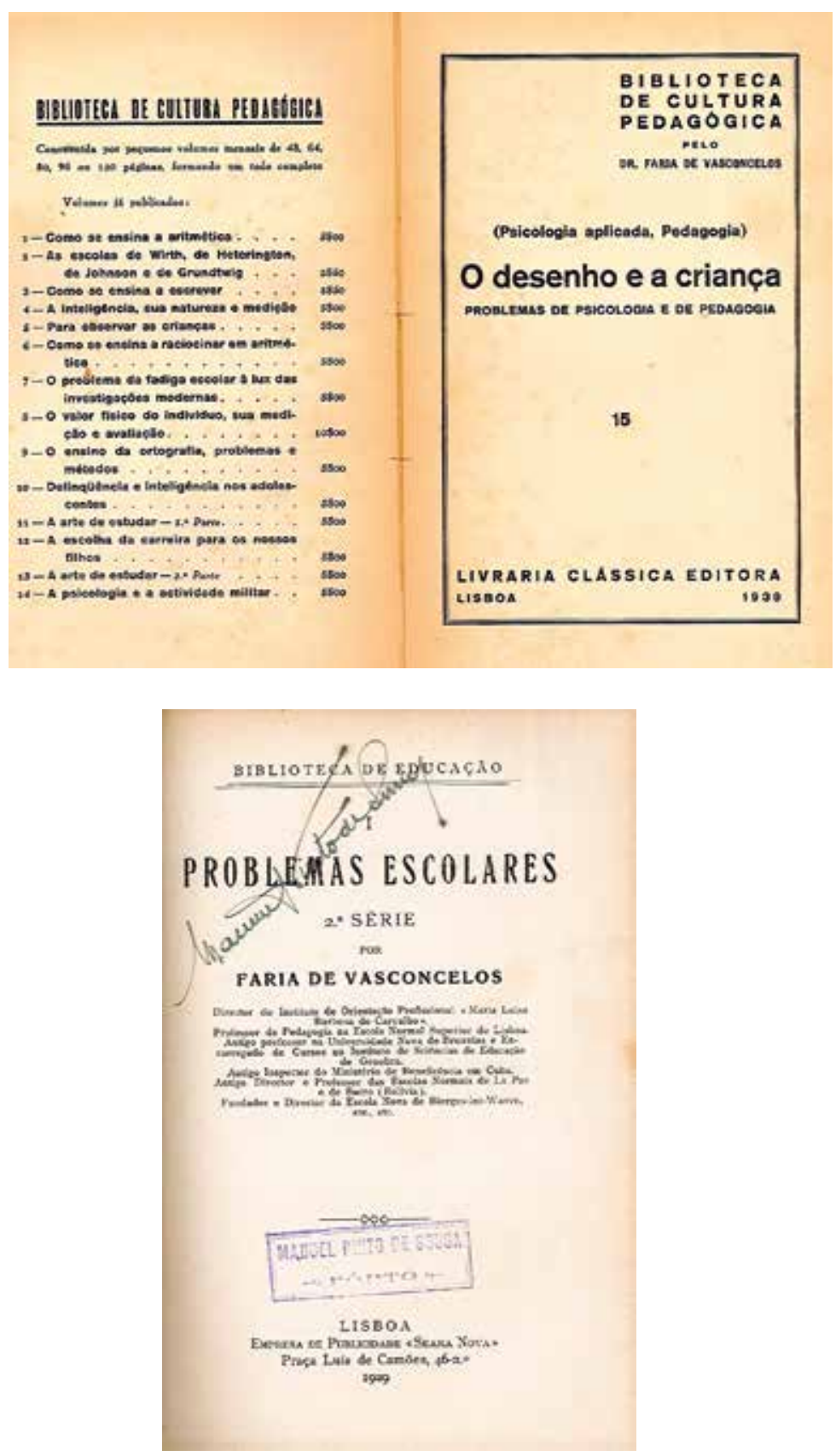

Faria foi un continuo tratadista de problemas escolares e de asuntos pedológicos e didácticos, tanto a través da edición de pequenos volumes, como mediante as suas Liçôes de Pedologia e Pedagogia experimental, ou a través da Revista Escolar, que promoveu com Joaquim Tomás. 
pedagogia especial, que deveria ser individualizada para os ditos 'anormais na escola' (retardados de inteligência, os instáveis ou nervosos e os mistos). Ora esta ideia norteou-se com os avanços da medicina, psiquiatria e psicologia que facilitaram o estudo das debilidades (mentais) nas suas repercussões pedagógicas ou comportamentais. A anormalidade patológica era uma das preocupações na época, que requeria mais conhecimentos e experiências psicopedagógicas, nos seus limites e consequências escolares. 0 próprio Vasconcelos no $2 .{ }^{\circ}$ Congresso Pedagógico, de $1909,{ }^{44}$ aborda as classificações de Decroly, Demoor, Yonekeere, De Santis, Bourneville e Philippe e de Boncour, ${ }^{45}$ esclarecendo quais são as crianças que devem ser admitidas para escolas de aperfeiçoamento, asilo-escola ou hospital para terem um tratamento especial.

0 pedagogista português foi convidado pelo conselheiro lldefonso Marques Mano (Diretor-Geral de Instrução Primária), em 1908, a elaborar um projeto sobre 0 ensino especial para crianças anormais e da sua organização, onde demonstrou conhecimentos e reflexões de vários pedagogistas, acreditando no papel conjunto do médico-professor na deteção de anormais patológicos e pedagógicos. Nos primeiros distingue entre os casos graves que devem seguir para escolas especiais e os menos graves para escolas de aperfeiçoamento. A própria escola, entendida como organização social, promovia disfunções no desenvolvimento dos alunos e daí os atrasos. Vasconcelos distingue entre o ignorante do retardado ou atrasado, em que este último devido à promiscuidade ou perversão o meio social envolvente apresentava dificuldades no aprender (atrasos). Propôs na base de fundamentos (psico) pedagógicos que para a escola funcionasse bem, devia detetar os atrasos nos escolares, pois este indicador de dificuldade mostraria as falhas de inteligência na criança e daí a necessidade de aplicar-se-Ihe testes. Um atraso escolar de 2 anos correspondia a um regime educativo diferente, submetendo 0 aluno a uma escola especial de aperfeiçoamento. Admitia Vasconcelos, que uma boa organização escolar e uma boa formação do professor e a colaboração do médico poderiam ser uma vantagem para o ensino dos atrasados patológicos e pedagógicos, para além da colaboração a família.

Ora essas reflexões e estudos em escolas de Lisboa permitiu-Ihe dar um ciclo de lições na Sociedade de Geografia, a convite da Liga de Educação Nacional e expostas em publicação e congresso pedagógico. ${ }^{46}$ Aí falou dessas crianças anormais escolares ou 'fracos de espírito' que eram seres invisíveis e desapercebidos em diversas situações pela família e na escola, pois em virtude da sua constituição física e mental eram incapazes de aproveitar os métodos de instrução/educação nas escolas. Na proposta de Lei para a Reorganização da Educação Nacional de João Camoesas - 1923 (D.G., II série, $\mathrm{n}^{0}$ 151, 2/julho/1923), que não chegou a vingar, mas teve como mentor Faria de Vasconce-

\footnotetext{
${ }^{44}$ António Faria de Vasconcelos, "These 1-Anormaes pedagógicos", In: $2^{\circ}$ Congresso Pedagógico de Instrução Primária e Popular-4a Seção, organizado pela Liga Nacional da Instrução-LNI em março (Lisboa: Atas-Anais da LNI, 1909), 347-354 (Fundo documental de Carvalhão Duarte/Simões Raposo -pasta 04532.044.

${ }^{45}$ Vid. Jean Philippe \& Georges Paul Boncour, Les anormalies mentales chez les écoliers. Étude Médicopédagogique (Paris: F. Alcan,1905).

${ }^{46}$ António Faria de Vasconcelos, Lições de Pedologia e Pedagogia Experimental, 38-59; Ibid. These 1-Anormaes pedagógicos, 349-350.
} 
los, compunha-se de 24 bases onde se propunha a criação de escolas para anormais, dos seguintes tipos: internatos no campo para anormais profundos- idiotas e imbecis; escolas autónomas para atrasados mentais, regime de semi-internato, nos arredores das grandes cidades. No diploma consta que a educação dos anormais deveria pautar-se pelo exame médico-psicológico aos educandos, com o objetivo de conseguir o seu maior rendimento pessoal e social. Ora por um lado, o teor argumentativo revela conhecimentos de psicometria e pedotecnia, dando a visão de que o deficiente quando reeducado podia tornar-se útil à sociedade e, por outro lado os tipos de escolas para anormais dá a antever classificações psicológicas em curso, na Europa, o que coincide com os conhecimentos de Faria de Vasconcelos. Mais tarde na década de 30 fará novos estudos com escolares em várias escolas do país desde o Instituto de Orientação Profissional, na perspetiva de diagnóstico psicopedagógico.

\section{Instituto de Reeducação Mental e Pedagógico (1929-1932): Escola de ensaio pedagógico}

Ao regressar a Portugal, em 1920, o foco pedagógico de atenção de Vasconcelos continuam a ser as crianças escolarizadas com anormalidades (atrasadas patológicas e pedagógicas no seu desenvolvimento físico-mental e na aprendizagem), não descorando as deficientes (graves ou leves nas suas capacidades mentais de inteligência, atenção, memória, vontade, linguagem e comunicação, etc.), e as 'normais' com regime especial (apoios e orientação pessoal e escolar). A falta de escolas especiais junto das escolas públicas e na sociedade levou advertir os responsáveis educativos na época, para o facto de ter aumentado o número de 'anormais' (dados estatísticos), devido às condições de vida social das famílias mais desfavorecidas, trabalhadores ou pobres, que agravaram esta problemática (30\% a $40 \%$ de crianças escolares tinham dificuldades de aprendizagem ou eram atrasadas). De facto, na época existiam no país: o Instituto Aurélio da Costa Ferreira (sexo masculino desde 1915), dirigido por Victor Fontes; Instituto Adolfo CoeIho-Casa Pia (masculino) e o Instituto Médico-pedagógico Condessa de Rilvas, em 1925 (designação de Florinhas da Rua em 1917), para dar um tratamento especializado a raparigas 'anormais' (físicas, psíquicas). Fora de Lisboa não havia respostas socioeducativas.

Foi com essa preocupação psicopedagógica e escolar que Faria de Vasconcelos realizou ações no Instituto de Orientação Profissional (IOP entre 1925-39) e propôs a criação do Instituto de Reeducação Mental e Pedagógico (IRMP entre 1929-32), ambos no Largo Trindade Coelho, $\mathrm{n}^{\circ} 21$ no $1 .^{\circ}$ e $2 .^{\circ}$ andar, este último com patrocínio da Junta Nacional de Educação (JEN), ${ }^{47}$ e tendo seções para: crianças anormais; atrasadas no desenvolvimento mental e estudos; crianças normais necessitadas de um regime especial de trabalho;

\footnotetext{
${ }^{47}$ A JEN-Junta de Educação Nacional, entidade particular de utilidade pública com grande atividade, criada em 6/09/1924 (D.G. n²020, I Série) liderada por Simões Raposo e de que fazia parte António Faria de Vasconcelos, Agostinho de Campos, Alfredo Bensaúde, António Sérgio, Jaime Cortesão, Jaime Magalhães, entre outros e cujo espólio se encontra no Arquivo do Instituto Camões (AIC-Lv. Atas da Assembleia Geral; Cx 0459, Proc. 1-2, Docs. 1-12), com menções ao IRMP (correspondência, subsídios). Vid. Augusto Pires Celestino da Costa, $A$ Junta de Educação Nacional, Sociedade de Estudos Pedagógicos, (Lisboa: Tip. Seara Nova, 1934): 6
} 
crianças débeis cujo desenvolvimento físico reclamava cuidados especiais; crianças com deficiências (linguagem, memória e atenção). Tinha a convicção que o IRMP, idêntico a outros congéneres na Europa e apetrechado com 7 laboratórios, com instrumentos variados para diagnóstico e experimentação, provenientes da Alemanha e Bélgica, permitia recolher elementos e dados oriundos do médico, escola, família e da comunidade para depois submetê-los à análise e à experimentação e, por isso, era '[...] une des manifestations les plus interessantes du Portugal moderne'. ${ }^{48}$ Faria de Vasconcelos baseou-se nos seus conhecimentos adquiridos e influências de ideias e experiências pedagógicas, durante a sua formação e permanência na Bélgica e Suíça, para criar o IOP (conceções de Claparède e Christiaens), sendo um estabelecimento pioneiro e dos mais creditados na Europa na organização escolar, ${ }^{49}$ tal como IRMP que foi um ensaio pedagógico com alguns pressupostos inovadores para educação especial. No dizer de J. Lopes Dias destinava-se: ${ }^{50}$

[...] à Educação Especial de crianças com lacunas de atenção, memória, da vontade, do raciocínio, da linguagem, ou com defeitos das capacidades mentais. Crianças que não entendem o que estudam, não progridem, menos por falta de desenvolvimento mental, do que pela maneira por que Ihes foi ensinado 0 que aprenderam, pelos efeitos e lacunas dos seus estudos! Em um e outro caso estas crianças carecem de cuidados especiais, de tratamento individual, de métodos e processos de educação e de ensino apropriado ao seu estado particular.

0 IOP funcionava na base de uma tríade de objetivos: as finalidades, a organização e o funcionamento. A finalidade era a de (re) educar os deficientes mentais e/ou físicos, os atrasados escolares ou 'fracos de espírito', dar-Ihes uma educação especial, incluindo as crianças, que pela sua constituição psicossomática, necessitavam de um apoio ou atenção específica e pedagógica. ${ }^{51} \mathrm{~A}$ estrutura organizacional compunha-se das seguintes seções: Secção para crianças com insuficiências graves ('défautes'), nas suas capacidades mentais; Secção para crianças atrasadas, quer no seu desenvolvimento mental, quer na aprendizagem escolar; Secção para 'crianças normais', mas com necessidade de uma tenção especial, na vida e no trabalho; secção para crianças cujo desenvolvimento exigia cuidados especiais (educação especial). As funcionalidades do instituto orientavam-se por uma estrutura de serviços de consulta (clínica psicopedagógica) e por um organismo de intervenção e tratamento, que era propriamente a parte (re) educativa na 'escola'.

\footnotetext{
${ }^{48}$ Joaquim Ferreira Marques, A. Faria de Vasconcelos: Obras Completas Vol. IV (1925-1933), 439; Vid. António Faria de Vasconcelos, Monographie de L'Institut de Reeducaction Mentale et Pedagogique (Lisboa: Imprensa Lucas \& $\left.C^{\mathrm{a}}, 1931\right)$.

${ }^{49} 0$ IOP tem registado no 'Livro de Visitas da época muitos personagens da Europa e América que consideravam o modelo a reproduzir nos seus países, por exemplo: Adolphe Ferrière, inspetores do Uruguai e Colômbia, responsáveis do Bureau International du Travai e do Reformatório de Madrid, de Pedro Isaac Rovira y Carrero (catedrático Direito Penal da Univ. Santiago de Compostela), Gerardo Seguel e J. Ferradu professores chilenos, Cecília Meireles e outras personagens brasileiras, etc.

50 Jaime Lopes Dias, Itinerário biobibliográfico de Faria de Vasconcelos, 104.

${ }^{51}$ Joaquim Ferreira Marques, A. Faria de Vasconcelos: Obras Completas Vol. IV (1925-1933), 437-438.
} 
Naquele estabelecimento realizavam-se: exames clínicos (antropométricos, fisiológicos); psicológicos para detetar aptidões sensoriais e mentais ao grau e tipo de conhecimentos adquiridos para especializar a aprendizagem para uma profissão e valores; pedagógicos para diagnostico das causas, natureza e amplitude dos defeitos e atrasos; intervenções e tratamentos psicopedagógicos segundo as tipologias de anomalias comportamentais, dependendo dos dados recolhidos. No diagnóstico das deficiências dessas crianças os técnicos pedagogistas procediam a uma série de exames clínicos, psicológicos e mentais (despistagem e diagnóstico), para depois estabelecer o tratamento, a correção, a educação e o ensino para essas crianças, dependendo dos dados e indícios dos exames feitos. 0 tratamento psicopedagógico era individualizado adaptando-se a cada caso específico da criança. De facto, o propósito consistia em salvar muitas crianças, que estavam condenadas a terem um percurso ‘anormal' na educação e na vida, dando-Ihes a possibilidade, por meio da intervenção social e pedagógica de usufruírem de uma série de exercícios, ocupações e atividades especiais, concretas, estimulantes e atrativas, de modo a recuperarem, dentro do possível, as condições 'normais' e o desenvolvendo ao máximo das suas capacidades ou aptidões. ${ }^{52}$

Por outro lado, Vasconcelos desenvolveu no IRMP uma dinâmica educacional reformadora, dentro da perspetiva (educação) social e/ou psicopedagógica moderna, em bases científicas, de tal modo que, a partir desta iniciativa, empenha-se na organização do Instituto Navarro de Paiva, já previsto na Lei de Proteção à Infância (D.G. $n^{0} 137$, de 14/06/1911) mas promulgado em 939 (Dec. №18375, de 17/5), em conformidade com 0 testamento do juiz conselheiro José da Cunha Navarro de Paiva, em 1924 (incumbida a Federação Nacional das Instituições de Proteção à Infância, desde 1930) destinado ‘[...] a menores do sexo masculino anormais delinquentes dos 9 aos 16 anos [...] suscetíveis de educação e capazes de fornecer um rendimento social pela prática dum ofício adequado às suas capacidades". ${ }^{53} \mathrm{Na}$ base desse Projeto organizacional Vasconcelos aprecia e indica 15 pontos estruturais: ${ }^{54}$

[...] é, mais uma vez, um documento direto, enxuto, sem adiposidades, estruturado em 15 pontos: 1 define a finalidade; 2 - define os condicionamentos médico-psicológicos de admissão; 3 - estabelece os limites tipológicos de admissão; 4 - apresenta as bases da organização educativa; 5 - indica as áreas da educação física compreendidas; 6 - faz 0 mesmo em relação à educação manual; 7 - faz o mesmo em relação à educação intelectual; 8 - identifica os ofícios em cuja aquisição aposta a educação profissional; 9 - prevê 0 encaminhamento externo do menor quando o Instituto não ensina 0 ofício para que ele revela aptidões; 10 - desenha a orientação geral a seguir no tocante à educação moral e social; 11 - estabelece a composição do pessoal docente; 12 - determina os critérios a seguir na distribuição dos menores em grupos; 13 - determina os limites de extensão desses grupos; 14 indica os serviços a prestar pelo Instituto: exames para o diagnóstico e tratamento psicopedagógico a seguir; assistência técnica no estudo dos casos particulares que se apresentem; orientação e inspeção psicopedagógica dos menores; 15 - determina o funcionamento, anexo ao Instituto "Dr. Navarro

\footnotetext{
${ }^{52}$ Vid. António Cunha, Faria de Vasconcelos: pensamento e ação pedagógica (Tese de Mestrado em Filosofia da Educação, IE da Univ. do Minho, 1997). Braga.

${ }^{53}$ Joaquim Ferreira Marques, A. Faria de Vasconcelos: Obras Completas Vol. IV (1925-1933), 443.

${ }^{54}$ Ibidem, 445-446.
} 
de Paiva", de um Patronato destinado à colocação, vigilância, amparo e auxílio material e moral dos menores que terminarem a sua educação.

J. Ferreira Marques encontrou no espólio deste pedagogista, ${ }^{55}$ atualmente na Secretaria - Geral do Ministério da Educação, um texto dactilografado, em papel timbrado do IRMP semelhante a esses pontos indicados para o Instituto Navarro de Paiva que demonstra que Vasconcelos sabia a forma organizacional que pretendia para uma instituição, com 0 intuito de salvar muitas crianças da inferioridade a que estavam condenadas na escola e sociedade, já que gravitavam no sistema educativo, aplicando-Ihes exercícios especiais, raios ultravioletas, hidroterapia, jogos, trabalhos manuais, ginástica médica e pedagógica. ${ }^{56} 0$ IRMP "[...] teve uma vida curta", já que "[...] foi efémero e sobre ele não há elementos' da sua atividade". ${ }^{57}$ Essa curta existência deveu-se, por um lado, à falta de apoios e financiamento estatal, de colaboradores e instituições educativas interessadas na educação especial e, por outro lado, o alheamento, incompetência educativa e pouco interesse das famílias das crianças na sua reabilitação, que eram as que mais dele necessitavam, assim como das escolas públicas onde muitas delas frequentavam 0 ensino oficial e da insuficiência técnico-científica dos professores para assegurarem essa educação. Poucos pedagogos na época entenderam as vantagens daquele instituto, quer como consulta às famílias e professores que lidavam com alunos anormais, quer no tratamento psicopedagógico.

Em 1930, Faria de Vasconcelos cria um Instituto Secundário, na modalidade de externato, para nele ministrar curso geral dos liceus em moldes de metodologia ativa e aplicar inovações psicopedagógicas para os jovens anormais e atrasados, frequentadores daquele nível de ensino público. Mas este projeto institucional também não teve êxito e continuidade pelas razões apontadas ao IRMP.

\section{Reflexões finais}

Faria de Vasconcelos considera "[...] A pedagogia é uma sciência autónoma, com um campo definido, com métodos de descrição e explicação que são seus, embora recorra às outras sciências que a auxiliam na sua missão", apresentando um espírito científico, um carácter dinâmico, funcional, social e diferencial e, ainda uma ação genética que tem em conta os interesses do educando e a influência do meio educativo envolvente. ${ }^{58} 0 \mathrm{u}$ seja," [...] a pedagogia contemporânea se inspira num elevado ideal filosófico de cultura individual e social", cujo ideal entende que "[...] a formação da personalidade deve assentar na cultura das aptidões caraterísticas do educando, sem descuidar as outras

\footnotetext{
55 Ibidem, XXII-XXIII.

${ }^{56}$ António Faria de Vasconcelos, Monographie de L'Institut de Rééducation Mentale et Pédagogique, 38-51.

${ }^{57}$ Joaquim Ferreira Marques, A. Faria de Vasconcelos: Obras Completas Vol. IV (1925-1933), XXIII.

${ }^{58}$ António Faria de Vasconcelos, "As características de educação contemporânea", Revista Seara Nova, 15/ outubro (1921): 17
} 
forças materiais e espirituais, sem desprezar nenhuma faculdade ou possibilidade", não havendo contradição entre pedagogia diferencial e integral. ${ }^{59}$

0 estudo científico da criança embebe a obra de Vasconcelos ressalvando a importância de diferenciar as crianças umas das outras antes de serem submetidas a algum método de ensino e, ainda em alertar os professores para atenderem às necessidades individuais e às particularidades fisiológicas e psicológicas de cada uma (saber se a criança estava apta para ser ensinada). ${ }^{60}$ Manifesta a importância da higiene escolar, 0 entendimento e colaboração entre professor-médico, a colaboração pedagógica da família à escola (influência alemã, francesa, inglesa e americana) e reflete as orientações da época sobre o processo de crescimento da criança (infância, adolescência e juventude), cada etapa ritmada em sequência de fases, ora lentas, ora aceleradas. ${ }^{61}$ Na verdade, os contributos (psico) pedagógicos de Vasconcelos à educação e pedagogia 'especial' de anormais assentou em ações práticas, propostas e publicações, fruto de reflexões e experimentações em instituições referidas. Propôs a criação de classes especiais para alunos sobredotados, como resposta ao problema da percentagem considerável deste tipo de escolares inteligentes nas escolas e da preocupação da família e professores, já que muitas vezes esses alunos perdiam-se (falta de atenção) nas aulas e desmotivavam-se pelos conteúdos e pela escola que não os compreendia. ${ }^{62}$

Em 1931, Vasconcelos apresentou à Sociedade das Nações um relatório sobre 0 exame racional dos alunos portugueses da escola primária submetidos à avaliação psicológica especializada para definir a sua orientação profissional, tendo concluído que a maioria ( $57 \%$ dos examinados) estava abaixo do valor médio de inteligência (QI). Neste grupo, comparou ainda a idade real com a idade mental e verificou que os nossos resultados eram mais desfavoráveis do que os obtidos em estudos semelhantes na Alemanha, Bélgica, Estados Unidos e França. Essa avaliação foi aplicada aos jovens com processos na Tutoria de Infância de Lisboa e, aí, os resultados mostraram que o seu Ql era inferior ao do grupo da escola primária, sendo $93 \%$ dos jovens anormais. Este problema preocupava os (psico)pedagogos, que experimentavam e aplicavam métricas que detetavam a quantidade de tipologias diversas. Para essa infância 'anormal', comparativamente com as normais na escola, no emprego e na sociedade era-Ihes impossivel regenerarem-se, tornando urgente a resolução desta questão social infantojuvenil. Participa, além disso, no Congresso da Associação Internacional de Proteção à Infância (Lisboa, outubro de 1931) protagonizando uma atuação multifacetada ao propor a formação mental e aquisição de conhecimentos com a compreensão da cultura física e moral do menor, com os serviços de orientação escolar, social e profissional que possibilitava ao sistema educativo uma via profissionalizante e humanizante. ${ }^{63} \mathrm{Na} 12 .{ }^{a}$ Sessão da Associação internacional para

\footnotetext{
${ }^{59}$ Ibidem.

${ }^{60}$ António Faria de Vasconcelos, Lições de Pedologia e Pedagogia Experimental, 10-15.

${ }^{61}$ Joaquim Ferreira Marques, Faria de Vasconcelos - Obras Completas, Vol. I (1900-1909), 267-268

${ }^{62}$ António Faria de Vasconcelos, "These 1 - Anormaes pedagógicos": 344-345.

${ }^{63}$ Joaquim Ferreira Marques, Faria de Vasconcelos - Obras Completas, Vol. IV (1925-1933): XXI-XXIII e 435439.
} 
a Proteção à Infância (Paris, 1937) insiste nos princípios básicos das funções psíquicas no desenvolvimento da criança anormal, ${ }^{64}$ que frequentava a escola, podendo recuperar-se com uma metodologia e intervenção individualizada. ${ }^{65}$

Por conseguinte, Vasconcelos propõe uma organização escolar tendo em conta os atrasados patológicos e pedagógicos na base de oito pontos para colmatar as anomalias graves dessas crianças com necessidade de tratamento especial: ${ }^{66}$ a criação de asilos-escola e escolas especiais (internato e semi-internato) e aulas especiais anexas às escolas primárias; avaliação pela comissão médico-pedagógica sobre a exclusão dos alunos das escolas normais (distribuição dos alunos normais nas aulas com máximo de 20 alunos, após diagnóstico); ensino simples, prático e individualizado (adaptado social); exames médico-pedagógicos com registos observacionais e de intervenção (caderneta); preparação específica dos professores nas escolas especiais; serviço de estatístico anual sobre crianças anormais; criação de comissões de proteção pós-escolar (tutela). Efetivamente, deviam ser retiradas das escolas primárias as crianças que tivessem anomalias menores, mentais, morais ou físicas, o que determinava um desenvolvimento físico-psíquico incompleto/irregular e, por isso eram admitidas em escolas de aperfeiçoamento evitando os métodos do ensino regular.

Na verdade, Vasconcelos dá uma atenção especial aos atrasados pedagógicos, que não sendo anormais mentais, estavam expostos à influência escolar e a múltiplos fatores e fenómenos envolventes e convertiam-se em anormais morais, viciosos, indisciplinados, etc. ${ }^{67}$ Daí ter pugnado por uma na associação eficaz 'médico-professor-escola', colaboração da família-escola e na habilitação/formação do professor.

\section{Bibliografia}

Alves, Manuela. “Compilação de Obras do prof. Faria de Vasconcelos". Estudos de Castelo Branco - Revista de História e Cultura 30 (1-7), (1969): 112-119

Amaral, Anabela. "Aprender a palavra ao ar livre. Estratégia de modernidade sanitária em Portugal no início do séc. XX”. História. Revista da FLUP (UPorto), IV série, vol. 6 (2016): 41-55.

Binet, Alfred \& Thomas Simon, Les enfants anormaux. Guide pour l'admission des enfants dans les classes de perfectionnement. Toulouse: Privat, 1905

Boto, Carlota. "Faria de Vasconcelos e a Escola Nova em Portugal: do self-government à educação científica”. Revista Brasileira de História da Educação, 19 (2019): 1-16.

\footnotetext{
${ }^{64}$ António Faria de Vasconcelos, Les Sanctions en éducation, leur légitime, leurs modes, leurs résultats (Bruxelles: Ed. Jean Vromans, 1937).

${ }^{65}$ António Faria de Vasconcelos, "L'examen rationnel des écoliers. Sélection scolaire au Portugal“, Bulletin International de la Protection de l'Enfance (1931): 146-153.

${ }^{66}$ António Faria de Vasconcelos, "These 1 - Anormaes pedagógicos": 345-346.

${ }^{67}$ A. Faria de Vasconcelos, Delinquência e inteligência nos adolescentes (Lisboa: Livraria Clássica Editora, 1936).
} 
Carpintero, Hélio. Historia de la Psicología en España. Madrid: Pirámide, 2004

Charlot, Bernard. Les sciences de l'éducation. Un enjeu, un défi. Paris: ESF, 1995

Claparède, Éduard. Como diagnosticar aptidões dos escolares. Trad. António Leal Júnior. Porto: Editora Educação Nacional, 1931

Costa, Augusto Pires Celestino da. A Junta de Educação Nacional, Sociedade de Estudos Pedagógicos. Lisboa: Tip. Seara Nova, 1934

Cruz, Ma Gabriel Moreno Bulas. “António Sena Faria de Vasconcelos (1880-1939: um português no movimento da Escola Nova”. Educação em Revista 2 (1) (2001): 139-148.

Cunha, António. Faria de Vasconcelos: pensamento e ação pedagógica(Tese de Mestrado em Filosofia da Educação, IE da Univ. do Minho, 1997). Braga.

Decroly, Ovide. Problemas de psicología y pedagogía. Madrid: Beltrán, 1929

Decroly, Ovide. Estudios pedagógicos y psicológicos sobre el niño anormal. Madrid: CEPE, 1933

Decroly, Ovide. El niño anormal. Madrid: Beltrán, 1934

Demoor, Jean. Les bases scientifiques de l'éducation. Bruxelles: Imp Université Libre, 1900

Demoor, Jean. As crianças anormais e o seu tratamento educativo em casa e na escola. Lisboa: C \& Editora, 1922

Dias, Jaime Lopes. "Itinerário biobibliográfico de Faria de Vasconcelos". Estudos de Castelo Branco -Revista de H. ${ }^{a}$ e Cultura -Monográfico 30 (1-7) (1969): 83-109

Duval, Nathalie. "L'Éducation nouvelle dans les sociétés européennes à la fin du XIXe siècle“. Revue Histoire, Économie \& Société (SEDES), année 21 (1) (2002): 71-86

Ferrière, Adolphe. L'éducation dans la famille. Neuchâtel \& Genève: Forum, 1921

Figueira, Manuel Henrique. Um roteiro da Educação Nova em Portugal. Lisboa: Livros Horizonte, 2004

Fonseca, Joaquim Augusto Ferreira da. Estudos Médico-Sociais sobre a Proteção a menores anormais e delinquentes. Lisboa: Tip. do Reformatório Central de Lisboa, 1930 
Gilbert, Marc Nicolas, Anne-Marie Châtelet, D. Lerch \& Jean-Noël Luc. "A escola ao ar livre. Uma experiência pedagógica e arquitetónica na Europa do século XX". História da Educação, 105 (2005): 101-106

Gomes, Joaquim Ferreira. "A. Faria de Vasconcelos”. Revista Portuguesa. Pedagogia, XIV (1980): 231-255

Gomes, Joaquim Ferreira. "A école de L'ermitage de Ovide Decroly". Revista Portuguesa de Pedagogia, Ano III, 1 (1962): 139-144

Larraz, José Ramón. La evolución económica de Bélgica. Madrid: Ed. Blass, 1946

Lemos, Álvaro Viana. Princípios basilares da Liga Internacional de Educação Nova e seus fins. Coimbra: Tip. Reis Gomes, 1929

Macedo de Oliveira, Joaquim Augusto. "2. ${ }^{\circ}$ Congresso Pedagógico de Instrução Primária -Liga Nacional de Instrução Primária". Occidente -Revista Illustrada de Portugal e do Estrangeiro, 1092 (30/abril) (1909), http://hemerotecadigital.cm-lisboa.pt/ OBRAS/Ocidente/Ocidente.htm (consultado 23/agosto 2020)

Majerus, Benoîte \& Veerle Massin. "Des psychiatres et des enfants : une histoire belge autour du congrès de 1937“. Revue d'Histoire d'Enfant 'Irrégulier', nº 18 (2016) :149-166

Marques, Joaquim Ferreira. Faria de Vasconcelos - Obras Completas, Vol. I (1900-1909). Lisboa: FCG, 1986.

Marques, Joaquim Ferreira. Faria de Vasconcelos - Obras Completas, Vol. II (1915-1920). Lisboa: FCG, 2000

Marques, Joaquim Ferreira. "Perspectivas internacionales en la historia de la psicología en Portugal”. Revista de Psicología General y Aplicada (Madrid), 53 (4) (2000): 599-606

Marques, Joaquim Ferreira. Faria de Vasconcelos - Obras Completas, Vol. III (1921-1925). Lisboa: FCG, 2006

Marques, Joaquim Ferreira. Faria de Vasconcelos - Obras Completas, Vol. IV (1925-1933). Lisboa: FCG, 2009

Marques, Joaquim Ferreira. Faria de Vasconcelos - Obras Completas, Vol. V (1933-1935). Lisboa: FCG, 2010a 
Marques, Joaquim Ferreira. Faria de Vasconcelos - Obras Completas, Vol. VI (1936-1939). Lisboa: FCG, 2010b

Martins, Ernesto Candeias. coord. António Faria de Vasconcelos nos meandros do Movimento da Escola Nova: Pioneiro da Educação do Futuro (Castelo Branco: Edição Câmara Municipal Castelo Branco Nárzea Rainha Imp., 2019

Martins, Ernesto Candeias. "0 ideário científico-pedagógico do escolanovista Faria de Vasconcelos (1880-1939) em prol duma escola nova, inovadora e atual". EccoS Revista Científica (Uninove-SP-Brasil), nº 48, jan./mar. (2019): 363-383

Martins, Ernesto Candeias. "0 movimento da escola nova e as tendências educativas geradas ao longo do séc. XX numa encruzilhada de teorias e práticas". In: $A$ Educação Comparada para além dos números. Contextos locais, Realidades nacionais e Processos transnacionais, ed. Carla Galego, $\mathrm{M}^{\mathrm{a}}$ Manuel Calvet Ricardo \& António Teodoro. 110-121. Lisboa: Edições Universitárias Lusófonas/ULH, 2019.

Martins, Ernesto Candeias. “G. Rouma e Faria de Vasconcelos nas Missões Belgas (1909 a 1920): Dos ideais da Escola Nova à Reforma Educativa liberal boliviana". In: Influencias Belgas en la Educación Española e Iberoamericana. coord. José Ma Hernández Díaz. 385-396. Salamanca: Ediciones Universidad de Salamanca, 2019

Philippe, Jean. \& Georges Paul Boncour, Les anormalies mentales chez les écoliers. Étude Médico-pédagogique. Paris: F. Alcan, 1905

Ramalho, Albano. Impressões sobre as Escolas de França e Bélgica. Porto: Casa Editora de A. Figueirinhas, 1909

Richelle, Marc, P. Jaussen \& S. Brédart. " Psychology in Belgiun“. Annual Review of Psychology, 43, (1992): 505-529

Vasconcelos, António Faria de. Lições de Pedologia e Pedagogia Experimental. Lisboa: Antiga Casa Bertrand, 1909.

Vasconcelos, António Faria de. "These 1-Anormaes pedagógicos" In: $2^{\circ}$ Congresso Pedagógico de Instrução Primária e Popular -4ª Seção, organizado em março pela Liga Nacional da Instrução -LNI. Lisboa: Imprensa Nacional, Atas- Anais da LNI, 1909

Vasconcelos, António Faria de. Une école nouvelle en Belgique. Paris/Neuchâtel: Delachaux \& Niestlé, 1915

Vasconcelos, António Faria de. Problemas escolares. $1^{\text {a }}$ Série. Lisboa: Editora Seara Nova, 1921 
Vasconcelos, António Faria de. "As características de educação contemporânea". Revista Seara Nova, 15 de outubro (1921): 17-18

Vasconcelos, António Faria de. Lições de psicologia geral, I. Lisboa: Livraria Editores Guimarães $C^{a}, 1924$.

Vasconcelos, António Faria de. "Contribuição para o estudo dos problemas relativos ao nível mental da população das escolas primárias de Lisboa". Boletim do Instituto de Orientação Profissional Maria Luísa Barbosa de Carvalho, 2-3 (1 ${ }^{\mathrm{a}}$ série/2a ed.), (1928): 11-17 e 19-22

Vasconcelos, António Faria de. Monographie de L'Institut de Reeducaction Mentale et Pedagogique. Lisboa: Imprensa Lucas \& C $C^{\text {a }}, 1931$

Vasconcelos, António Faria de. "L'examen rationnel des écoliers. Sélection scolaire au Portugal“. Bulletin International de la Protection de l'Enfance, (1931): 146-153.

Vasconcelos, António Faria de. "Decilagens de tempos de reação de 2346 crianças das escolas de Lisboa". Boletim do Instituto de Orientação Profissional Maria Luísa Barbosa de Carvalho, 23 (junho), (1935): 3-10

Vasconcelos, António Faria de. Delinquência e inteligência nos adolescentes. Lisboa: Liv. Clássica Editor, 1936.

Vasconcelos, António Faria de. Les Sanctions en éducation, leur légitime, leurs modes, leurs résultats. Bruxelles: Ed. Jean Vromans, 1937

Vasconcelos, António Faria de. "Alguns problemas de psicologia da aprendizagem". Boletim do Instituto de Orientação Profissional Maria Luísa Barbosa de Carvalho, 25 (dezembro), (1937): 19-36.

Vasconcelos, António Faria de. "Princípios fundamentais do método de A. G. Christiaens". Boletim do Instituto de Orientação Profissional, 26 (junho), (1938): 3-7

Vasconcelos, António Faria de. Uma Escola Nova na Bélgica (Prefácio de A. Férrière, Pósfácio e Notas de C. Meireles Coelho), tradução do francês por C. Meireles-Coelho, A. Cotovio e L. Ferreira. Aveiro: UA Editora -Universidade de Aveiro - FCT, 2015

Vermeylen, Guillaume. Lois débiles mentales. Madrid : Hernaudo Ed., 1926

Vial, Monique. Les enfants anormaux à l'école : aux origines de l'éducation spécialisée, 1882-1909. Paris: Colin, 1900 